\title{
Swallowed Metallic Spoon Causing Doudeno-Jejunal Junction Perforation in a 13-Year-Old Child: Case Report
}

\author{
Seifu Alemu' \\ Nebiyou S Bayileyegn' \\ Melkamu Berhane Arefayine $\mathbb{( D}^{2}$ \\ 'Department of Surgery, Jimma \\ University, Jimma, Ethiopia; ${ }^{2}$ Department \\ of Pediatrics and Child Health, Jimma \\ University, Jimma, Ethiopia
}

Background: A child swallowing a long metallic spoon is an extremely rare phenomenon. Foreign bodies longer than $6 \mathrm{~cm}$ are unlikely to pass through the gastrointestinal tract spontaneously and require endoscopic or surgical removal in order to avoid associated complications, such as visceral perforations.

Case Details: A 13-year-old child presented with accidental swallowing of a metallic spoon 10 days prior to hospital admission. He had history of loss of appetite, epigastric and left upper quadrant abdominal pain and started to have high grade intermittent fever 11 days after swallowing the spoon. A plain abdominal radiograph revealed a metallic spoon in the midabdomen. An exploratory laparotomy revealed an $11 \mathrm{~cm}$ long metallic spoon impacted at the duodeno-jejunal junction with walled off perforation and erosion of the mesentery of the colon. The metallic spoon was removed and the perforated site was repaired. The surgery was smooth and the patient recovered fully and was discharged seven days post-operation.

Conclusion: A swallowed long metallic spoon is unlikely to pass spontaneously and should be removed as soon as possible in order to avoid associated complications like impaction, perforation and subsequent peritonitis.

Keywords: foreign body, doudeno-jejunal junction, spoon, case report

\section{Introduction}

Foreign body ingestion is a frequent occurrence particularly in the pediatric age group and adults with psychiatric illnesses, but swallowing a long metallic spoon in the pediatric age group is an extremely rare scenario. The majority of swallowed foreign bodies do not require specific treatment since they pass through the digestive tract spontaneously without causing any significant complications. Less than $1 \%$ of the cases become complex with gastrointestinal tract perforations, which are often caused by sharp objects, warranting surgical intervention., ${ }^{1,2}$

There are different options of removing foreign bodies from the gastrointestinal tract including minimally invasive procedures like endoscopic or laparascopic removal as well as open surgical removal. The decision to use which option depends on several factors like the site of the foreign body and presence or absence of complications like perforations and peritonitis. Minimally invasive procedures are preferable over open surgery for objects located in the stomach and duodenum and when there are no perforations, peritonitis or pneumo-peritoneum. However, if these minimally invasive procedures fail or if there are other indications for open removal, one should go ahead for open removal without delay. Minimally invasive
Correspondence: Melkamu Berhane Arefayine

Tel $+251-912066170$

Email melkamuarefayine@gmail.com 
procedures have advantages over open surgical removal since they are associated with less post-operative pain, lower incidence of wound infection, and minimal surgical stress. $^{3-6}$

Given the rarity of the case, we hereby report a 13years-old male with doudeno-jejunal junction perforation secondary to swallowing a long metallic spoon.

\section{Case Presentation}

A 13-year-old child presented to the pediatric outpatient department 10 days after accidentally swallowing a metallic spoon while playing with his younger sibling. He had history of abdominal pain and loss of appetite, but no history of nausea, vomiting, dysphagia, fever, voice change or bowel habit change. The family was aware that their child swallowed a metallic spoon and was waiting for spontaneous passage in stool. Otherwise, he was perfectly healthy, his development is age appropriate and he did not have any symptoms of behavioral or psychiatric disorders.

Physical examination on the date of admission to the hospital revealed a comfortable child with stable vital signs and a soft and non-tender abdomen with no any sign of peritonitis. Complete blood count was in the normal range and a plain abdominal radiograph revealed a metallic foreign body (spoon) in the mid-abdomen (Figure 1). On the next day of admission, he started to have high grade intermittent fever and epigastric and left upper quadrant abdominal pain. A repeat abdominal

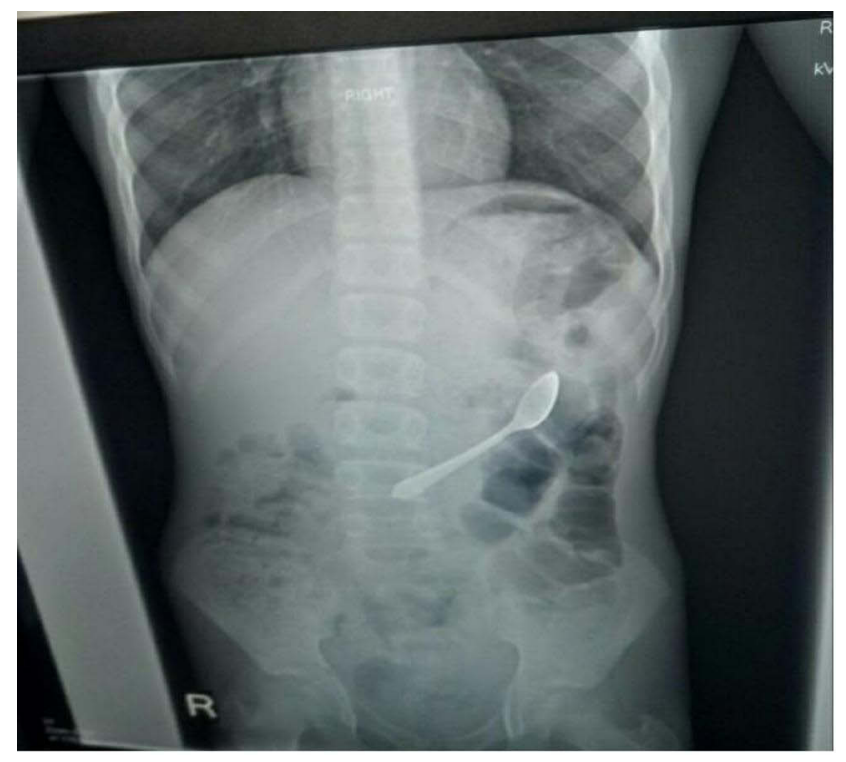

Figure I Plain abdominal X-ray showing swallowed spoon.

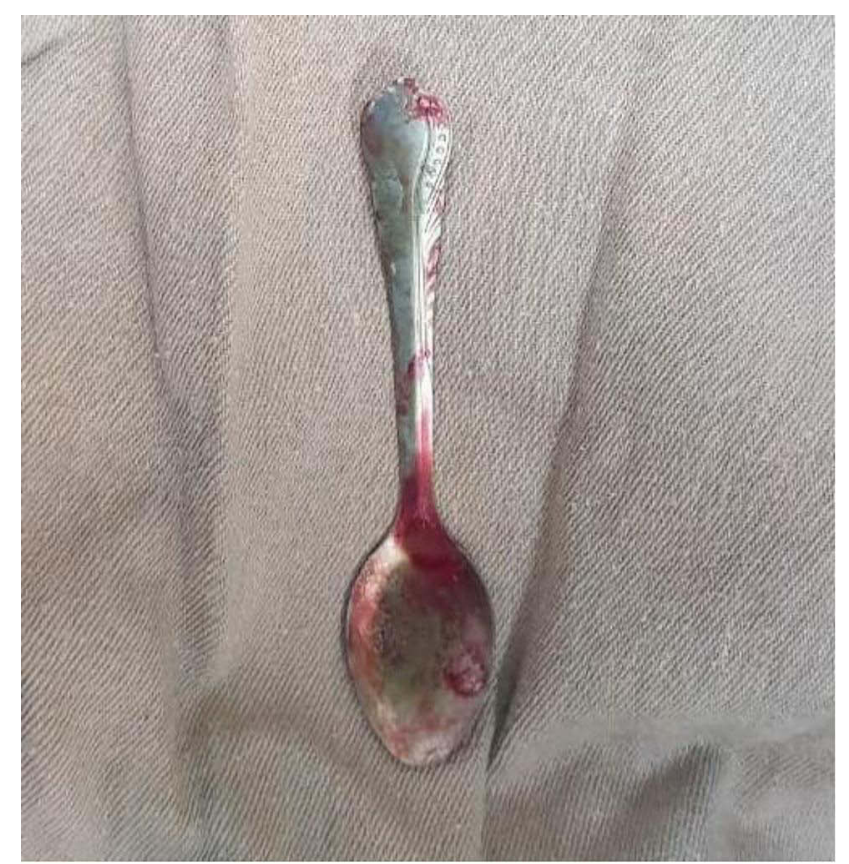

Figure 2 Metallic spoon removed from doudeno-jejunal junction.

radiograph did not show any progress. Hence, an exploratory laparotomy was done which revealed an $11 \mathrm{~cm}$ long metallic spoon (Figure 2) impacted at duodeno-jejunal junction with walled off perforation and erosion of the mesentery of the colon (splenic flexure). The perforated part measured about $3 \times 3 \mathrm{~cm}$ and had necrotic edges, but the blood supply to the rest of the bowel was intact. There was no intra-abdominal collection or intestinal content spillage. The perforated site was approached with right medial visceral rotation and duodeno-jejunal junction mobilization with division of Treitz's ligament. Necrotic edges were refreshed and a double layer Heineke-Mikulicz type repair was done (Figure 3). The surgery was smooth, the patient recovered fully after the surgery, and was discharged seven days post-operation and did not complain of anything on subsequent followups.

\section{Discussion}

Swallowed small-sized foreign bodies generally pass through the gastrointestinal tract without complications, while large, sharp or caustic ingested foreign bodies in the gastrointestinal tract will usually cause complications such as impaction, obstruction or perforation. Particularly, objects longer than $6 \mathrm{~cm}$ are usually unable to pass through the duodenal sweep. ${ }^{1,2}$ Our case was among these rare events which resulted in impaction and perforation. 


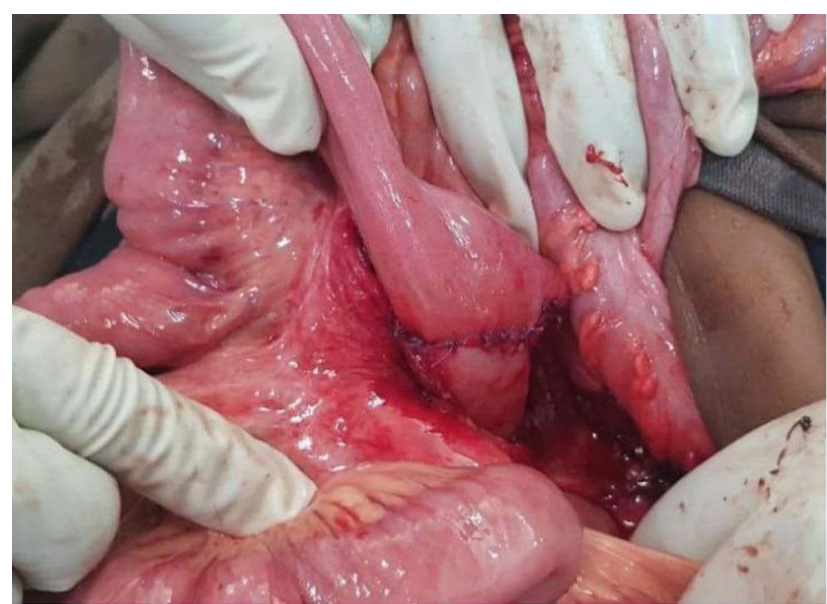

Figure 3 Repaired perforation site (DJ junction).

To date, less than 30 cases of swallowed metallic spoons have been reported in the medical literature and all of them occurred in adults. ${ }^{7-9}$ Moreover, in most of the cases, the patients are either elderly (senile), had underlying psychiatric disorders or were alcohol intoxicated at the time of the incident ${ }^{1-3,9}$ and in some of the cases, the swallow occurred accidentally. ${ }^{7,10,11}$ Surprisingly, some of the patients did not even remember when and how they swallowed the spoon/s and were diagnosed incidentally. ${ }^{8}$ Our patient and his parents were however aware of the swallow but were expecting spontaneous expulsion, which is unlikely to happen. Even if the time of presentation of the patients reported so far ranged from few hours ${ }^{7,10,11}$ to several years ${ }^{8,9}$ none of them had perforation, ${ }^{3,7-11}$ unlike in our case where there was doudeno-jejunal perforation. The possible reason behind the occurrence of the perforation in our case might be the mismatch between the larger size of the spoon and the smaller size of the lumen of the intestine, leading to impaction of the spoon with subsequent necrotic changes and ultimate perforation. Imaging studies like CT scans play a key role in the management of swallowed objects as they enable one to localize the site and facilitate removal. ${ }^{4,6}$ In our case, a CT scan was not done as the service is not available on an emergency basis and we did not want to delay the intervention waiting for the CT scan as the child had already developed signs of peritonitis. All the patients reported so far did well postoperatively after the spoons were removed ${ }^{3,7-9}$ and similarly, our patient had a smooth post-operative course and was discharged without any complications. Ingested large or long foreign bodies $(>6 \mathrm{~cm})$ should be removed within
24 hours since these foreign bodies cannot pass the duodenum or ileocecal valve spontaneously. ${ }^{1,2}$ In all of the cases reported so far, the swallowed metallic spoons were removed either endoscopically, ${ }^{3,10,11}$ or surgically., ${ }^{3,-9}$ Even if removal can be done surgically or through endoscopy, the site of the foreign body and presence of complications like perforations and peritonitis affect the choice of which option to use. ${ }^{3-6}$ In our case, we carried out the removal through open surgery as there was no specialized facility or expertise to perform an endoscopic/laparascopic removal; additionally, the child has already developed signs of peritonitis necessitating open surgical intervention.

\section{Conclusion}

Swallowed large metallic spoons are less likely to pass spontaneously and hence should be removed as soon as possible after diagnosis in order to avoid associated complications such as perforation. Hence, patients/care givers should visit health facilities and health workers should go for removal of such foreign bodies as soon as the diagnosis is made and expectant management should be avoided.

\section{Ethical Consideration}

As this was a case report, institutional approval for publication was not required. However, the parents of the infant have given us their written consent to publish the case and the images.

\section{Acknowledgment}

We would like to thank the parents for giving us their consent to report the case.

\section{Disclosure}

The authors declare that they have no conflicts of interest related to this work.

\section{References}

1. Lee JH. Foreign body ingestion in children. Clin Endosc. 2018;51 (2):129-136. doi:10.5946/ce.2018.039

2. Uyemura MC. Foreign body ingestion in children. Am Fam Physician. 2005;72(2):287-291.

3. Velitchkov NG, Grigorov GI, Losanoff JE, Kjossev KT. Ingested foreign bodies of the gastrointestinal tract: retrospective analysis of 542 cases. World J Surg. 1996;20(8):1001-1005. doi:10.1007/s002 689900152

4. Mulita F, Papadopoulos G, Tsochatzis S, Kehagias I. Laparoscopic removal of an ingested fish bone from the head of the pancreas: case report and review of literature. Pan Afr Med J. 2020;36:123. doi:10.11604/pamj.2020.36.123.23948 
5. Dal F, Hatipoğlu E, Teksöz S, Ertem M. Foreign body: a sewing needle migrating from the gastrointestinal tract to pancreas. Turk J Surg. 2018;34(3):256-258. doi:10.5152/turkjsurg.2017.3391

6. Mima K, Sugihara H, Kato R, et al. Laparoscopic removal of an ingested fish bone that penetrated the stomach and was embedded in the pancreas: a case report. Surg Case Rep. 2018;4(1):149. doi:10.1186/s40792-018-0559-4

7. Song Y, Guo H, Wu J-Y. Travel of a mis-swallowed long spoon to the jejunum. World J Gastroenterol. 2009;15(39):4984. doi:10.3748/ wjg. 15.4984

8. Shamim AA, Zuberi MM, Shariff AH. Laparoscopic retrieval of two intragastric spoons at least seven years after ingestion. Laparosc Endosc Robot Surg. 2019;2(3):77-79. doi:10.1016/j.lers.2019.06.002
9. Deeba S, Purkayastha S, Jeyarajah S, Darzi A. Surgical removal of a tea spoon from the ascending colon, ten years after ingestion: a case report. Cases J. 2009;2(1):7532. doi:10.4076/1757-16262-7532

10. Shen C-S, Su Y-C. Endoscopic retrieval of mis-swallowed table spoon. Case Rep Gastroenterol. 2019;13(1):32-36. doi:10.1159/ 000496223

11. Kim SI, Jung SY, Song CE, Shim DB. Unusual foreign body, a spoon, in the esophagus of a middle-aged female: a case report and review of the literature. Ear Nose Throat J. 2020;22: 014556132094268. doi:10.1177/0145561320942680

\section{Publish your work in this journal}

The International Medical Case Reports Journal is an international, peer-reviewed open-access journal publishing original case reports from all medical specialties. Previously unpublished medical posters are also accepted relating to any area of clinical or preclinical science. Submissions should not normally exceed 2,000 words or 4 published pages including figures, diagrams and references. The manuscript management system is completely online and includes a very quick and fair peer-review system, which is all easy to use. Visit http://www.dovepress.com/testimonials.php to read real quotes from published authors. 